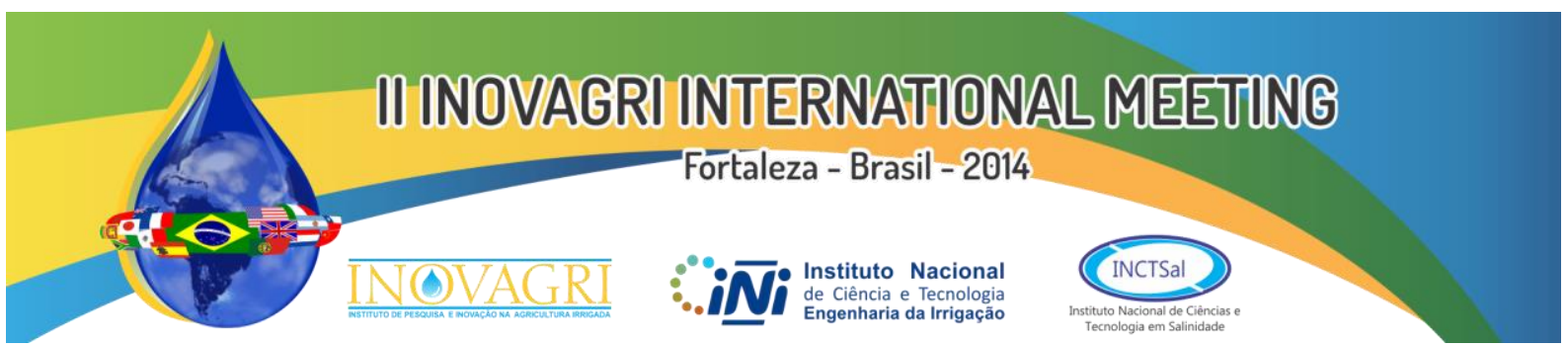

http://dx.doi.org/10.12702/ii.inovagri.2014-a168

\title{
RENDIMENTO DA MAMONEIRA BRS GABRIELA SUBMETIDA A DIFERENTES NÍVEIS DE IRRIGAÇÃO
}

\author{
C. P. de M. Costa ${ }^{1}$, H. O. C. Guerra ${ }^{2}$, J. H. Zonta ${ }^{3}$, É. S. A. B. de Almeida ${ }^{4}$, W. P. Araújo ${ }^{5}$, J. R. Pereira ${ }^{3}$
}

RESUMO: Com o objetivo de avaliar o comportamento agronômico da mamoneira BRS Gabriela submetida a diferentes lâminas de irrigação, um ensaio experimental foi conduzido no Campo Experimental da Embrapa Algodão, no município de Barbalha, CE. Foi utilizado um delineamento experimental de blocos ao acaso com distribuição em faixas, com 4 repetições, totalizando 24 parcelas. Os tratamentos foram distribuídos em 6 lâminas de irrigação, aplicando 150, 125, 100, 75, 50 e 25\% da evapotranspiração da cultura (ETc), estimada por Penman-Monteith. As variáveis analisadas foram altura da planta, diâmetro do caule, número de racemos por planta, comprimento do racemo primário, altura de inserção do primeiro racemo, número de frutos no racemo primário, área foliar, peso de 100 sementes e produtividade total. Os dados foram submetidos à análise de variância e regressão. Houve efeito significativo das laminas de irrigação apenas sobre a altura de planta, área foliar e produtividade da cultivar BRS Gabriela. As demais variáveis não foram influenciadas pelas laminas de irrigação, mesmo assim, destacou-se a lâmina aplicada de $75 \%$ da ETc, $(474,4 \mathrm{~mm})$, quanto ao máximo crescimento e produtividade da mamoneira. Com os resultados, observa-se que a cultivar BRS Gabriela apresenta potencial para crescimento e cultivo irrigado mesmo em regiões com escassez hidrica. A cultivar BRS Gabriela é muito sensível ao encharcamento do solo, visto que a mesma não suportou a aplicação de laminas de irrigação superior ao recomendado.

PALAVRAS-CHAVES: Ricinus communis L., déficit hídrico, tolerância.

\section{YIELD OF BRS GABRIELA CASTOR BEAN UNDER DIFFERENTS DEPTHS OF IRRIGATION}

SUMMARY: Aiming to evaluate the agronomic performance of castor bean BRS Gabriela subjected to different irrigation levels, experimental testing was conducted at the Experimental Station of Embrapa Cotton, in the municipality of Barbalha, Ceará. An experimental design of randomized blocks, with 4 replicates, totaling 24 plots was used. The treatments were distributed in 6 irrigation levels, applying 150 , $125,100,75,50$ and $25 \%$ of crop evapotranspiration ( ETc ), estimated by Penman - Monteith method. The variables evaluated were plant height, stem diameter, number of racemes per plant, length of the primary raceme, height of insertion of the first raceme, number of fruits in the primary raceme, leaf area, 100 -seed weight and yield. Data were subjected to analysis of variance and regression. Significant effect of the irrigation levels were observed only on plant height, leaf area and yield of BRS Gabriela. The other variables were not influenced by irrigation levels, yet stood out the level applied to $75 \%$ of ETc (474.4 $\mathrm{mm}$ ) in maximum growth and yield of castor bean. With the results, it is observed that BRS Gabriela has

\footnotetext{
${ }^{1}$ Mestrando em Engenharia Agrícola, Universidade Federal de Campina Grande, UFCG, Campina Grande - PB. Email: cpcaca@ hotmail.com

$2 \mathrm{PhD}$, Professor Titular do Departamento de Engenharia Agrícola, UFCG, Campina Grande - PB. Email: hugo_carvallo@hotmail.com

${ }^{3}$ Dr. e M.Sc., Pesquisadores da Embrapa Algodão. Email: joao-henrique.zonta@embrapa.br; jose.r.pereira@embrapa.br

${ }^{4}$ Engenheira Agrônoma, Estagiária da Embrapa Algodão. Email: ericasamara@ gmail.com

${ }^{5}$ Doutorando em Engenharia Agrícola, Universidade Federal de Campina Grande, UFCG, Campina Grande - PB. Email: wpacordao@hotmail.com
}
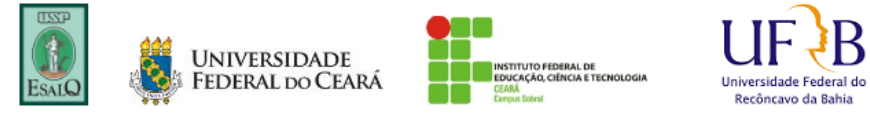
potential for growth and irrigated even in regions with water scarcity. The BRS Gabriela is very sensitive to waterlogging, since it did not support the application of blades exceeding the recommended irrigation.

KEYWORDS: Ricinus communis L., water deficit, tolerance.

\section{INTRODUÇÃO}

A mamoneira (Ricinus communis L.) é uma das mais de 7.000 espécies da família Euphorbiaceae, possivelmente originária do leste da África, na Etiópia, sendo a Índia, a China, o Brasil e a Rússia os principais países produtores mundiais (FAO, 2012). É uma oleaginosa com grande tolerância à seca, exigente em calor e luminosidade, adaptando-se perfeitamente ao semiárido brasileiro (CARTAXO et al., 2004) e tem sido muito explorada em função do óleo contido em suas sementes que se constitui em matéria-prima para a produção do biodiesel (BELTRÃO et al., 2003).

No Brasil, a mamoneira tem ganhado destaque desde que seu cultivo começou a ser incentivado como a principal oleaginosa na região semiárida para integrar o Programa Brasileiro de Biodiesel. Estudos indicam que a demanda atual de óleo para a produção de combustíveis menos poluentes tem provocado demanda para o aumento das áreas exploradas com essa cultura.

O programa de biodiesel prevê uma forte participação da agricultura familiar, principalmente em regiões como o Nordeste do país, com a utilização de óleo extraído de espécies como a mamona. O biodiesel, em particular quando produzido a partir deste tipo de oleaginosas cuja produção é viável em pequena agricultura, oferece uma oportunidade única de geração de emprego associada à sustentabilidade ambiental. Devido ao apelo econômico e social da cultura, uma série de trabalhos de pesquisa é conduzida na região Nordeste, visando à melhoria das técnicas de manejo e buscando materiais genéticos mais produtivos e adaptados a cada microrregião.

Programas de melhoramento, que contemplam a geração, avaliação e indicação de cultivares, são fundamentais no processo para implantação e desenvolvimento de culturas socioeconomicamente importantes como é o caso da mamona. Tais pesquisas devem ser regionalizadas de modo a permitir maior segurança à atividade agrícola, na tentativa de dar resposta a problemáticas específicas.

A escassez, o uso inadequado, a poluição, a contaminação e o desperdício do recurso "água", são temas chave nas agendas de debates de diversas instituições públicas ou privadas. Dessa forma, estudos que sirvam de base para um futuro desenvolvimento de variedades mais tolerantes ao estresse hídrico não só tem importância para áreas com limitação agrícola devido à falta de água, mas também como fator de produção a ser economizado em sistemas irrigados.

$\mathrm{O}$ uso da irrigação na agricultura encarece a cadeia produtiva e para que se justifique tal uso, faz-se necessário que se tenham altas produtividades. Para isso torna-se necessário o uso de cultivares que melhor respondam a disponibilidade hídrica, bem como o manejo hídrico mais adequado, que trará maiores produtividades com menores custos e de forma sustentável.

Considerando-se as limitações em relação aos recursos hídricos das regiões semiáridas do nordeste, estudos a respeito da tolerância à seca de plantas, como a mamona, são muito necessários.

Diante do exposto, objetivou-se, com o presente trabalho, verificar o comportamento produtivo da mamoneira BRS Gabriela submetida a diferentes regimes hídricos no solo, na tentativa de identificar se o material genético tem potencial para tolerância às condições de estresse hídrico.

\section{MATERIAL E MÉTODOS}

O experimento foi conduzido no Campo Experimental da Embrapa Algodão, no município de Barbalha - CE, localizado nas coordenadas geográficas $7^{\circ} 19^{\prime} \mathrm{S}$ de latitude, $39^{\circ} 18^{\prime} \mathrm{O}$ de longitude e 409,03 m de altitude (RAMOS et al., 2009).

Antes da instalação do experimento foi realizada coleta de amostras de solo deformadas e indeformadas, na área experimental, para determinação das características químicas (macronutrientes) e físicas (porosidade total, macro e microporosidade, densidade do solo, curva característica de retenção de água no solo e textura).

O preparo do solo foi realizado com subsolagem e gradagem, sendo a calagem e adubação de fundações realizadas de acordo com a recomendação para a cultura da mamoneira em função da 
análise de solo. Os tratos culturais (controle de plantas invasoras, pragas e doenças, e adubação de cobertura) foram realizados de acordo com as recomendações da cultura.

As parcelas experimentais tiveram dimensão de 6 linhas de plantio com 7 metros de comprimento, sendo considerado área útil as 4 linhas centrais, e 5 metros de comprimento. A área total ocupada pelo experimento foi de $1.644 \mathrm{~m}^{2}(30 \times 54,8)$ com a área da parcela de $7,5 \times 10,8\left(81,0 \mathrm{~m}^{2}\right) \mathrm{e}$ uma área útil de 7,0 x 7,2 (54,4 $\left.\mathrm{m}^{2}\right)$ com 6 fileiras duplas, 4 fileiras duplas úteis, 12 fileiras simples e 8 fileiras simples úteis na parcela com uma área do bloco de 30,0 x 10,8 $\left(324 \mathrm{~m}^{2}\right)$.

O delineamento experimental utilizado foi o de blocos ao acaso com distribuição em faixas, com 4 repetições totalizando 24 parcelas. Os tratamentos foram distribuídos em 6 lâminas de irrigação $(150,125,100,75,50$ e $25 \%$ da evapotranspiração da cultura (ETc)), correspondente a uma lamina total aplicada de $(872,67,739,91,607,16,474,4,341,64$ e 208,88 mm). A ETc foi estimada multiplicando-se a evapotranspiração de referência $\left(\mathrm{ET}_{0}\right)$, obtida através do método de PenmanMonteith FAO-56, pelo coeficiente da cultura Kc (FAO 56) (ALLEN et al., 1998), com turno de rega fixo de 2 dias. Os dados meteorológicos para o cálculo da $\mathrm{ET}_{0}$ foram obtidos da Estação Meteorológica automática do Instituto Nacional de Meteorologia-INMET, localizada na região de Barbalha - CE.

O método de irrigação adotado foi do tipo localizado, utilizou um sistema de irrigação por gotejamento, com 1 linha de gotejadores para cada fileira dupla, com gotejadores espaçados de modo a se formar uma faixa molhada. As irrigações foram realizadas a cada 2 dias.

A adubação baseou-se na análise química do solo e exigências nutricionais da cultura. Foi aplicado o equivalente a $33 \mathrm{~kg}$ de $\mathrm{N} \mathrm{ha}^{-1}$ e $150 \mathrm{~kg}$ de $\mathrm{P}_{2} \mathrm{O}_{5}$ ha $^{-1}$, tendo sido usado como fonte do nutrientes o sulfato de amônio, fosfato de monoamônio (MAP) e o sulfato de potássio.

A cultivar BRS Gabriela foi semeada diretamente no solo em covas abertas manualmente nas parcelas no dia 21 de agosto de 2013, sendo colocados 2 sementes por cova. A germinação deu-se a partir do $5^{\circ}$ dia após a semeadura (DAS). No $7^{\circ}$ e no $13^{\circ}$ DAS foi observado $85 \%$ e $99 \%$ de germinação, respectivamente. No dia 3 de setembro de 2012 procedeu-se o desbaste deixando 1 planta por cova.

Aos 100 dias após a emergência foram feitas avaliações altura da planta, diâmetro do caule, número de racemos, comprimento do racemo primário, altura de inserção do primeiro racemo, número de frutos no racemo primário, área foliar, peso de 100 sementes, produtividade total.

Os dados obtidos foram submetidos à análise de variância e regressão.

\section{RESULTADOS E DISCUSSÃO}

Nas Figuras 1, 2, 3, 4, 5, 6, 7, 8 e 9 são apresentados os gráficos que relacionam os valores da altura da planta, diâmetro do caule, número de racemos por planta, comprimento do racemo primário, altura de inserção do primeiro racemo, número de frutos no racemo primário, área foliar, peso de 100 sementes, produtividade total na mamoneira BRS Gabriela em função das lâminas de irrigação (níveis de ETc) aplicadas ao solo.

Na Figura 1, observa-se que a altura média das plantas da mamoneira BRS Gabriela foi influenciada pelas lâminas de irrigação aplicadas ao solo. As laminas aplicadas de 25,50 e $100 \%$ da ETc, não diferenciaram entre si. Como também, as lâminas de 75 e 100\% da ETc, também não diferenciaram entre si. A lâmina de irrigação que melhor proporcionou crescimento em altura da mamoneira BRS Grabriela foi a de $75 \%$ da ETc (Figura 1).

De acordo com a Figura 2 observa-se que o diâmetro do caule das plantas da mamoneira BRS Gabriela não foi influenciado pelas laminas de irrigação aplicadas ao solo. Observa-se também, que o diâmetro do caule apresentou comportamento crescente à medida que aumentou as lâminas de irrigação $(25,50,75$ e $100 \%$ da ETc), com destaque para a lâmina de $100 \%$ da ETc, apresentando maior valor quanto ao parâmetro avaliado.

Quanto ao número de racemo por planta, essa variável não foi influenciada pelas lâminas de irrigação aplicadas, destacando-se a lâmina de $75 \%$ da ETc, correspondente ao maior número de racemo por planta (Figura 3).

Na Figura 4 em relação ao comprimento do racemo primário da mamoneira também se observou um comportamento crescente na medida em que aumentou a lâmina de irrigação. Essa 
variável também não foi afetada pelas lâminas de irrigação, mesmo assim, destacou-se a lâmina de $100 \%$ da ETc.

Quanto a altura de inserção do primeiro racemo, essa variável não foi influenciado pelas lâminas de irrigação aplicadas, destacando-se as lâminas de 25 e $75 \%$ da ETc, correspondente ao maior número de racemo por planta (Figura 5).

Na figura 6 se constatou que não houve diferença entre a média do número de frutos no racemo primário entre as lâminas de irrigação aplicadas, mesmo assim, destacou-se a lamina de 50\% da ETc entre as demais lâminas aplicadas.

A área foliar da mamoneira BRS Gabriela foi influenciada pelas laminas de irrigação aplicada (Figura 7). As laminas aplicadas de 25, 50 e $100 \%$ da ETc não diferenciaram entre si. Como também, as laminas de 25,75 e $100 \%$ da ETc, obtiveram mesmo comportamento. De maneira geral, destacou-se a lâmina de $75 \%$ da ETc.

Quanto ao peso médio de 100 sementes, essa variável não foi influenciado pelas lâminas de irrigação aplicadas, destacando-se a lâmina $75 \%$ da ETc (Figura 8).

$\mathrm{Na}$ figura 9 se constatou que houve efeito significativo entre a média da produtividade total entre as lâminas de irrigação aplicadas. Nas laminas de 50 e $100 \%$ as médias não foram diferenciadas. Como também, as laminas de 75 e $100 \%$, também não se diferenciaram entre si. De maneira geral, destacou-se a lamina de $75 \%$ da ETc, entre as demais lâminas aplicadas, como a de maior produtividade.

Para as lâminas maiores a redução e a morte das plantas como constatadas nas lâminas de $125 \mathrm{e}$ $150 \%$ da ETc, deve ter ocorrido devido ao excesso hídrico, que tem como a principal consequência a diminuição da concentração de oxigênio, o que dificulta a respiração radicular e acarreta outros problemas, como: parada do processo ativo de absorção de nutrientes (o qual depende da respiração) e ocorrência de respiração anaeróbia pela planta e pelos microrganismos do solo, causando acúmulo de substâncias tóxicas como metano, etileno e gás sulfídrico (PIRES et al., 2002; BELTRÃO \& SOUZA, no prelo apud BELTRÃO et al., 2003). Já nas lâminas de irrigação menores, os menores valores provavelmente, ocorreram devido ao déficit hídrico que provoca o fechamento dos estômatos, diminuindo a assimilação de $\mathrm{CO}_{2}$ e, consequentemente, diminuindo as atividades fisiológicas das plantas, principalmente a divisão e o crescimento das células, (DOBASHI et al., 1998; SCHURR et al., 2000; REGO et al., 2004; VIDAL et al.,2005) refletindo assim em uma menor produtividade.

\section{CONCLUSÕES}

Com os resultados, observa-se que a cultivar BRS Gabriela apresenta potencial para crescimento e cultivo irrigado mesmo em regiões com escassez hidrica, visto que sua maior produtividade foi alcançada com a lamina de $75 \%$ da ETc. A cultivar BRS Gabriela é muito sensível ao encharcamento do solo, visto que a mesma nao suportou a aplicação de laminas de irrigação superior ao recomendado.

\section{REFERÊNCIAS BIBLIOGRÁFICAS}

BELTRÃO, N. E. de M; CARDOSO, G. D. Informações sobre o sistema de produção em condições irrigada: Condições gerais. Campina Grande, 2003, 4 p. (Documentos, 132).

BELTRÃO, N. E. M.; CARDOSO, G. D.; SEVERINO, L. S. Sistemas de produção para a cultura da mamona na agricultura familiar no semi-árido nordestino. Campina Grande: Embrapa Algodão, 2003. Folder.

BELTRÃO, N. E. de M.; SOUZA, J. G. de; SANTOS, J. W. dos; JERÔNIMO, J. F.; COSTA, F. X.; LUCENA, A. M. A. de; QUEIROZ, U. C. de. Fisiologia da mamoneira, cultivar BRS-149 Nordestina na fase inicial de crescimento, submetida a estresse hídrico. Revista brasileira de oleaginosas e fibrosas, Campina Grande: Embrapa Algodão, v. 7, n. 1, p. 659-664. jan-abr. de 2003.

CARTAXO, W. V.; BELTRÃO, N. E. M.; SILVA, O. R. R. F.; SEVERINO, L. S.; SUASSUNA, N. D.; SOARES, J. J. O cultivo da mamona no semi-árido brasileiro. Campina Grande: Embrapa Algodão, 2004. 20p. (Embrapa Algodão . Circular Técnica, 77). 
DOBASHI, A. M.; CARVALHO, J. A.; PEREIRA, G. M.; RODRIGUES, L. S. Avaliação do crescimento da boca de leão (Antirrihimum majus) submetido a diferentes níveis de deficiência hídrica. In: CONGRESSO BRASILEIRO DE ENGENHARIA AGRÍCOLA, 27., 1998, Poços de caldas. Anais... Poços de caldas: Sociedade Brasileira de Engenharia Agrícola, 1998. v. 1, p. 100102.

FAO. Food and Agriculture Organization of the United Nations. Disponível em: http://www.fao. Org/. Acesso em: 30 set. 2012.

PIRES, J. L. F.; SOPRANO, E.; CASSOL. B. Adaptações morfofisiológicas da soja em solo inundado. Pesquisa Agropecuária Brasileira, v. 37, n. 1, p. 41-50, jan.2002. http://dx.doi.org/10.1590/S0100-204X2002000100006

RAMOS, A. M.; SANTOS, L. A. R. dos; FORTES, L. T. G (Orgs.) Normais climatológicas do Brasil: 1961-1990. Brasília: INMET, 2009. 465p.

REGO, J. L.; VIANA, T. V. A.; AZEVEDO, B. M.; BASTOS, F. G. C.; GONDIM, R. S. Efeitos de níveis de irrigação sobre a cultura do crisântemo. Revista Ciência Agronômica. Fortaleza: v.35, n.2, p.302-308, 2004.

VIDAL, M. S.; CARVAlho, J. M. F. C.; MENESES, C. H. S. G. Déficit Hídrico: Aspectos Morfofisiológicos. Campina Grande, 2005. 19p. (Embrapa Algodão. Documentos, 142).

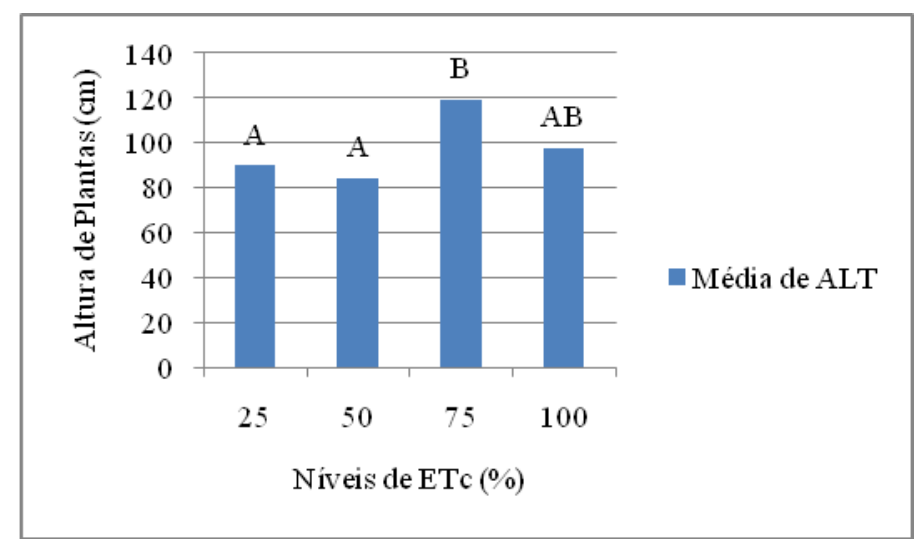

Figura 1. Média de altura de planta $(\mathrm{cm})$ da cultivar BRS Gabriela em função das lâminas de irrigações aplicadas ao solo. Barbalha, CE, 2013.

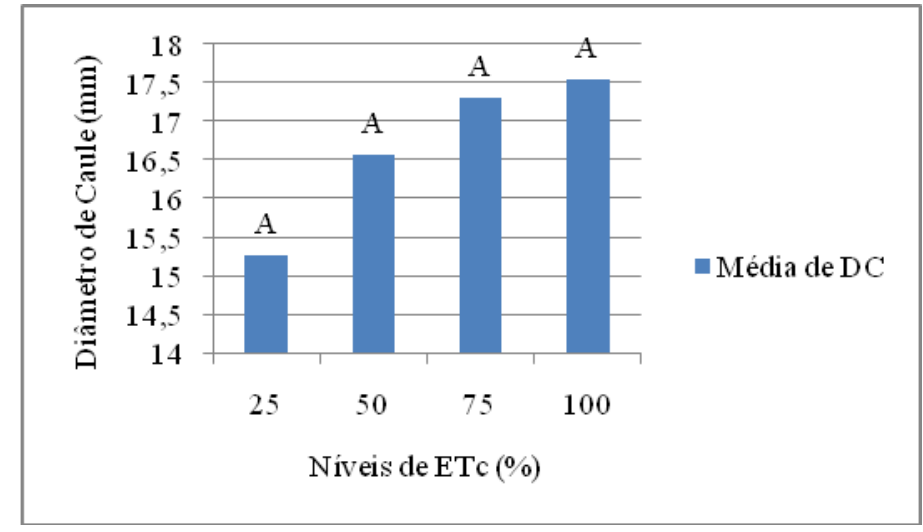

Figura 2. Média do diâmetro de caule (mm) da cultivar BRS Gabriela em função das lâminas de irrigações aplicadas ao solo. Barbalha, CE, 2013. 
C. P. de M. Costa et al.

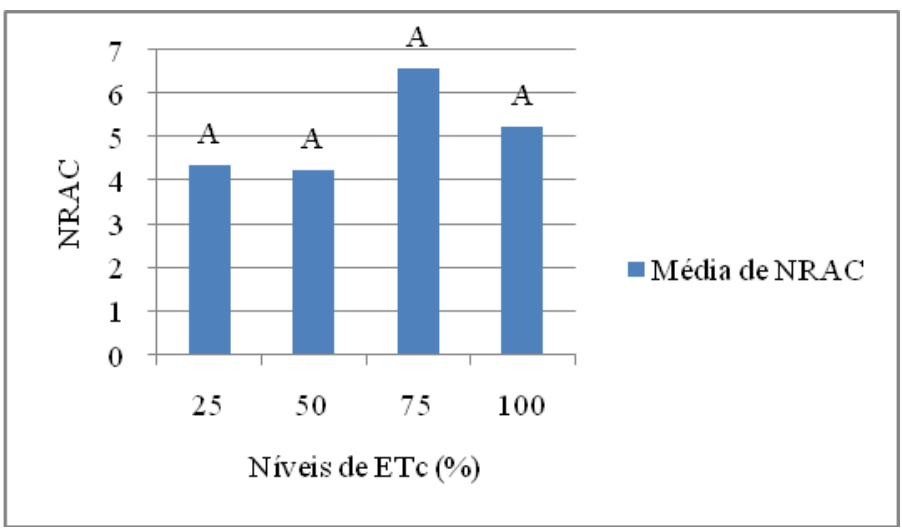

Figura 3. Média de números de racemos por planta da cultivar BRS Gabriela em função das lâminas de irrigações aplicadas ao solo. Barbalha, CE, 2013.

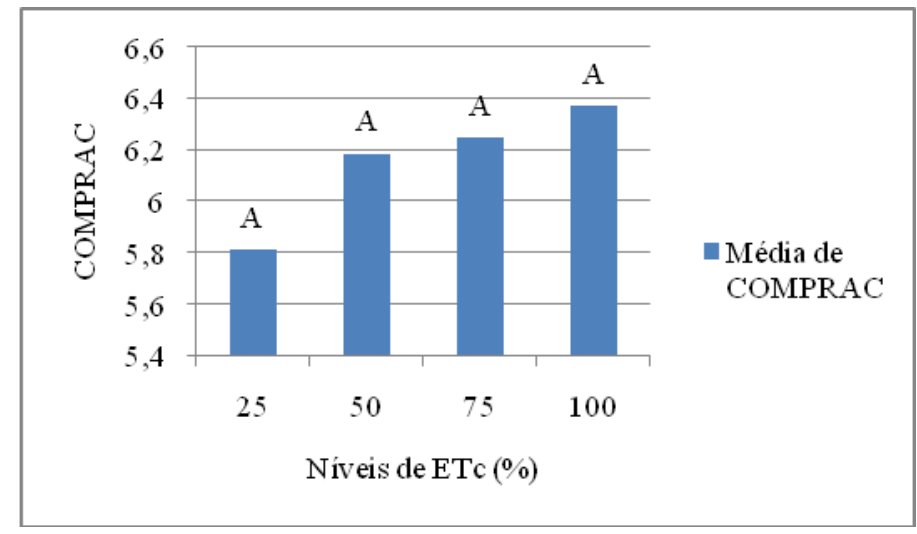

Figura 4. Média de comprimento do racemo primário $(\mathrm{cm})$ da cultivar BRS Gabriela em função das lâminas de irrigações aplicadas ao solo. Barbalha, CE, 2013.

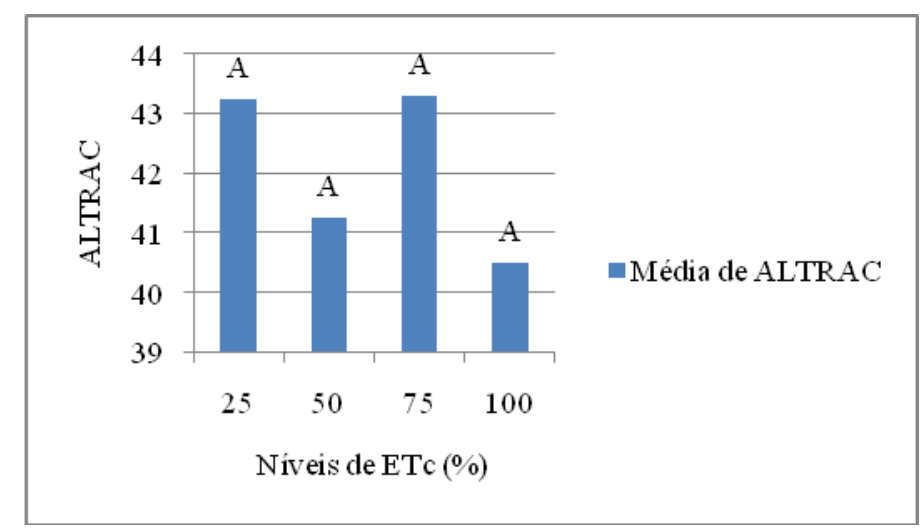

Figura 5. Média de altura de inserção do primeiro racemo $(\mathrm{cm})$ da cultivar BRS Gabriela em função das lâminas de irrigações aplicadas ao solo. Barbalha, CE, 2013. 


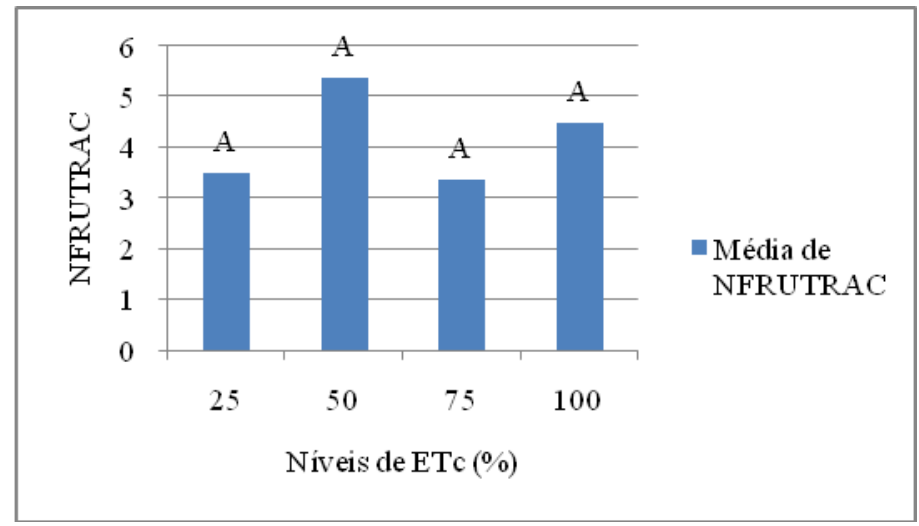

Figura 6. Média de número de frutos no racemo primário da cultivar BRS Gabriela em função das lâminas de irrigações aplicadas ao solo. Barbalha, CE, 2013.

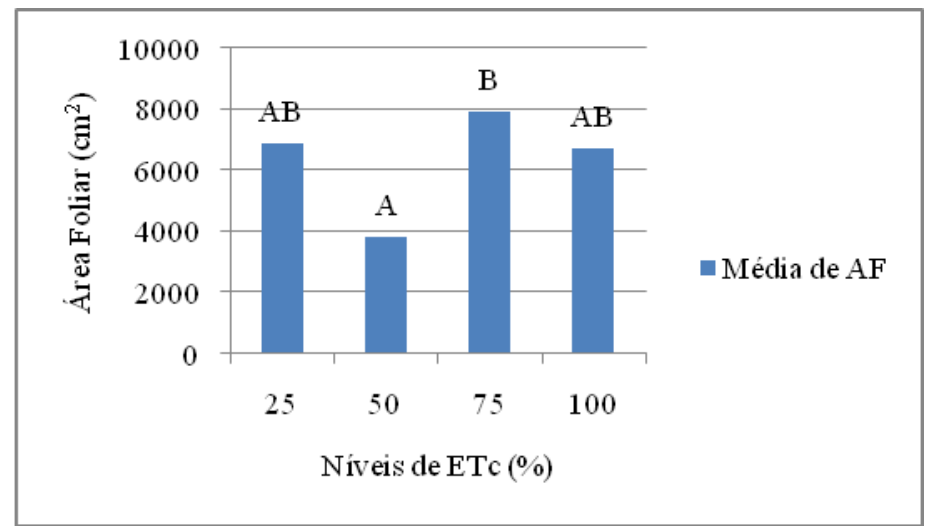

Figura 7. Média da área foliar $\left(\mathrm{cm}^{2}\right)$ da cultivar BRS Gabriela em função das lâminas de irrigações aplicadas ao solo. Barbalha, CE, 2013.

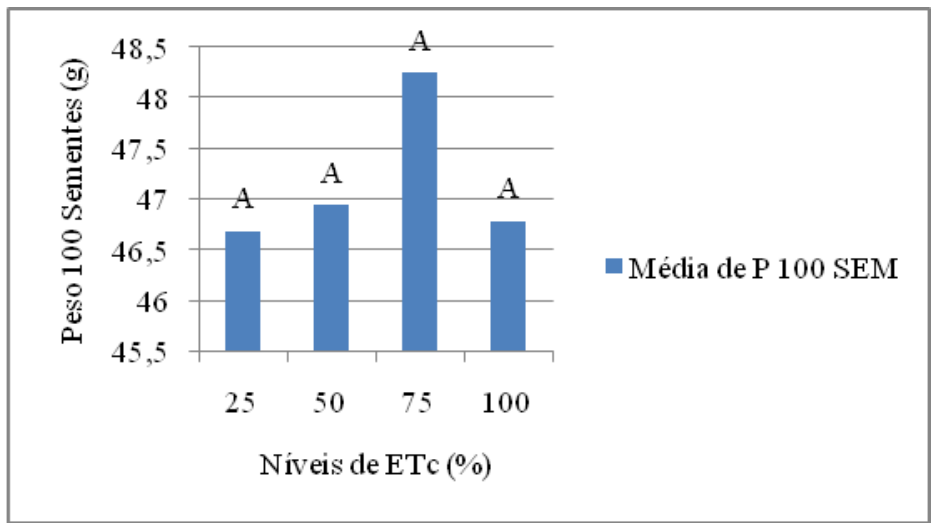

Figura 8. Média de peso de 100 sementes (g) da cultivar BRS Gabriela em função das lâminas de irrigações aplicadas ao solo. Barbalha, CE, 2013. 
C. P. de M. Costa et al.

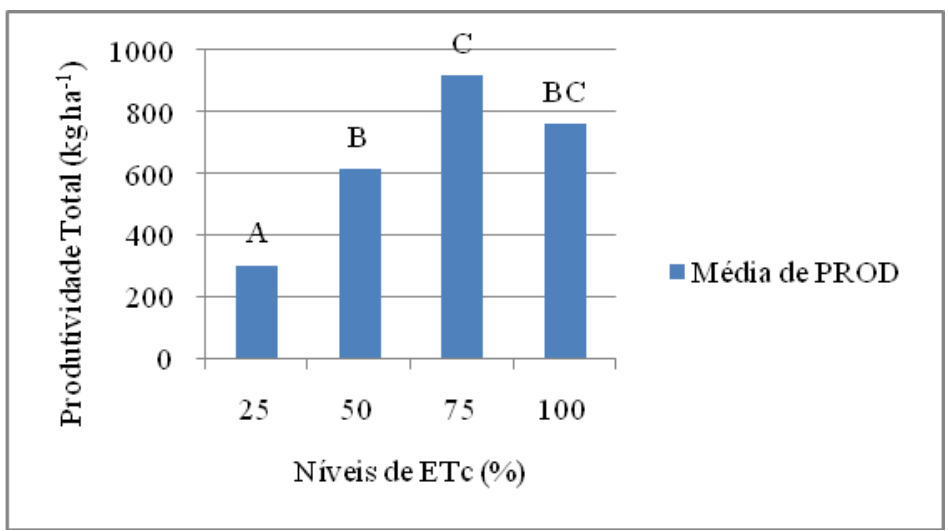

Figura 9. Média de produtividade total $\left(\mathrm{kg} \mathrm{ha}^{-1}\right)$ da cultivar BRS Gabriela em função das lâminas de irrigações aplicadas ao solo. Barbalha, CE, 2013. 